\title{
Retórica humanitaria y expulsabilidad: migrantes haitianos y gobernabilidad migratoria en Chile*
}

\section{Humanitarian rhetoric and expulsability: Haitian migrants and migration governance in Chile}

\author{
Fernanda Stang Alva** \\ Centro de Investigación en Ciencias Sociales y Juventud, Universidad Católica Silva \\ Henríquez (CISJU-UCSH), Santiago, Chile. \\ Antonia Lara Edwards*** \\ Centro de Investigación en Ciencias Sociales y Juventud, Universidad Católica Silva \\ Henríquez (CISJU-UCSH), Santiago, Chile. \\ Marcos Andrade Moreno**** \\ Facultad de Ciencias Jurídicas y Sociales, Universidad Austral de Chile, Puerto Montt, \\ Chile.
}

* Este artículo se vincula al proyecto FONDECYT N 3190674 "Migración, precariedad y ciudadanía: de las tácticas de subsistencia a las estrategias de lucha".

** Doctora en Estudios Sociales de América Latina, Universidad Nacional de Córdoba. Académica investigadora de la línea Migraciones, Interculturalidad y Derechos Humanos del Centro de Investigación en Ciencias Sociales y Juventud, Universidad Católica Silva Henríquez (CISJU-UCSH), Santiago, Chile. Correo electrónico: fstang@ucsh.cl

*** Doctora en Ciencias Sociales por la Universidad de Chile. Licenciada en Psicología por la Universidad Diego Portales. Magíster en Psicoanálisis por la Universidad Andrés Bello. Docente investigadora de la línea Migraciones, Interculturalidad y Derechos Humanos del Centro de Investigación en Ciencias Sociales y Juventud, Universidad Católica Silva Henríquez (CISJU-UCSH), Santiago, Chile. Correo electrónico: alara@ucsh.cl

**** Doctor en Derecho por la Universitat Pompeu Fabra, Licenciado en Ciencias Jurídicas y Sociales y Magíster en Derecho por la Universidad de Chile. Facultad de Ciencias Jurídicas y Sociales, Universidad Austral de Chile, Puerto Montt, Chile. Correo electrónico: marcos.andrade@uach.cl 


\title{
Resumen
}

En este artículo se analiza el vínculo entre el argumento humanitario y de derechos humanos y el efecto restrictivo, e indirectamente expulsor, de las medidas recientes tomadas en Chile respecto de la migración haitiana. El texto muestra que esta estrategia de apelación a la retórica humanitaria constituye un elemento central del paradigma de la gobernabilidad migratoria, enfoque que sirve de sustento al régimen global de gestión/control de las migraciones, y que se ha ido cristalizando en el pensamiento del Estado chileno sobre la migración internacional desde mediados de la década de 2000. Se conectan además estas medidas con las adoptadas por otros países sudamericanos, en un escenario de regionalización de este régimen.

Palabras clave: Migración haitiana; gobernabilidad migratoria; régimen global de gestión/control de las migraciones.

\begin{abstract}
This article analyzes the link between humanitarian and human rights considerations and the restrictive and indirectly expulsion-orientated effect of recent measures taken in Chile with respect to Haitian migrants. The text reveals that the strategy of appealing to humanitarian rhetoric represents a central element of the paradigm of migratory governance, and is an approach that supports the global regime for the management/control of migration, one that has been materializing in the Chilean State's consideration of international migration since the mid-2000s. These measures are also connected with those adopted by other South American countries, in a scenario of the regionalization of this regime.
\end{abstract}

Keywords: Haitian migration; migration governance; global regime for the management/control of migration.

\section{Introducción}

Chile se ha convertido en la última década en un destino emergente de la migración intrarregional (Martínez \& Orrego, 2016), lo que ha contribuido a conformar un escenario migratorio muy dinámico y relativamente cambiante. En el último par de años, se ha observado el crecimiento acelerado de dos grupos nacionales en particular: los venezolanos, cuya presencia se incrementó en un 347\% entre abril de 2017 y diciembre de 2018 -según datos censales (INE, 2018) y estimaciones del INE y el Departamento de Extranjería y 
Migración (INE y DEM, 2019)-, y los haitianos, que aumentaron en un 286\% en el mismo período, aunque venían haciéndolo desde antes.

Estos son, precisamente, los grupos principales en torno a los cuales se tomaron medidas administrativas específicas a las pocas semanas de instalado un nuevo gobierno en el país. Para los haitianos en particular, grupo del que se ocupa este trabajo, se establecieron una Visa Consular de Turismo Simple para ingresar al país, una Visa Humanitaria de Reunificación Familiar, con un máximo anual de visados, y unos meses después se comenzó a implementar un "Plan Humanitario de Regreso Ordenado al País de Origen para Ciudadanos Extranjeros”, que a pesar de no precisar un país de origen de quienes podrían postular, estuvo orientado a este grupo nacional, de acuerdo a varias señales,

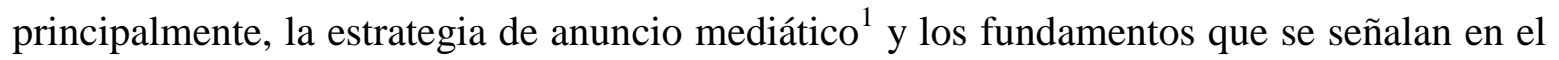
documento que lo crea $^{2}$.

En este artículo se analiza este conjunto de medidas gubernamentales, poniendo el foco en la última. El problema de investigación del que partimos se pregunta cómo se articula el discurso humanitario y de derechos humanos, que aparece como fundamento de estas medidas administrativas, con el efecto restrictivo que han tenido en la práctica sobre dicho flujo migratorio. En efecto, según el Anuario 2018 de Asistencia Consular, del Ministerio de Relaciones Exteriores, durante 2018 se entregaron solamente 112 visas consulares de turismo simple y 114 visados humanitarios de reunificación familiar a los haitianos ${ }^{3}$, mientras que en 2017 habían entrado a Chile como turistas 111.761 personas de este origen. El objetivo del trabajo, por lo tanto, fue explorar el vínculo entre el argumento humanitario y de derechos humanos y el efecto restrictivo (e implícitamente expulsor) de las medidas, tanto en relación con el escenario nacional como con el contexto sudamericano, para encontrar una explicación plausible de esta aparente contradicción. El artículo parte con un breve apartado en el que se presenta el marco conceptual que está en la base del análisis, y otro dedicado a una sintética descripción de la metodología utilizada y las concepciones que la sustentan. Luego se exponen las medidas administrativas tomadas recientemente en Chile respecto de la migración haitiana, que conforman el objeto de ese análisis, y a continuación, las que se han tomado en el escenario sudamericano. Descrito este contexto, el trabajo se concentra en el análisis específico del Plan de retorno, y paso seguido, en una propuesta de lectura desde el enfoque adoptado, procurando una respuesta a la pregunta de

1 Véase, por ejemplo, en línea, <https://www.24horas.cl/nacional/gobierno-explica-como-funcionara-elplan-humanitario-de-regreso-ordenado-para-extranjeros-2840338>;

<https:/www.emol.com/noticias/Nacional/2018/08/30/918926/Gobierno-implementara-Plan-

Humanitario-de-Regreso-Ordenado-para-haitianos-a-su-pais.html>;

$<$ https://www.latercera.com/nacional/noticia/los-detalles-del-plan-humanitario-retorno-ordenado-delgobierno/364644/>; > > >ttps://www.elmostrador.cl/noticias/pais/2018/08/30/gobierno-anuncia-el-planhumanitario-de-regreso-ordenado-para-ayudar-a-haitianos-que-quieran-volver-a-su-pais/ $>$.

2 Resolución Exenta No 5744 (26/10/2018), Ministerio del Interior y Seguridad Pública y la Subsecretaría del Interior, Dispone plan humanitario de regreso ordenado al país de origen de ciudadanos extranjeros.

3 En línea, https://issuu.com/minrel_chile/docs/anuario_consular_2018_cancilleria_c. 
investigación planteada. Las conclusiones, además de buscar sintetizar el análisis desarrollado en el texto, enuncian algunos aspectos no abordados por el trabajo, pero que es necesario considerar.

\section{Breves notas sobre el enfoque conceptual}

Dos nociones principales son las que están detrás de la mirada analítica que se propone en este artículo: la de régimen global de gestión/control de las migraciones (Kalm, 2008; Mezzadra, 2012; Mezzadra \& Neilson, 2016), y la de gobernabilidad migratoria. La primera es tributaria de la propuesta de Sandro Mezzadra, quien alude con esta idea a un régimen

estructuralmente híbrido de ejercicio de la soberanía, en cuya definición y en cuyo funcionamiento concurren los Estados nacionales (...), formaciones 'posnacionales' como la Unión Europea, nuevos actores globales como la Organización Internacional para las Migraciones y organizaciones no gubernamentales con finalidades 'humanitarias' (Mezzadra, 2005, p. 147-148).

Este régimen, según explica el autor, no se propone cerrar herméticamente las fronteras de los países receptores,

sino establecer un sistema de diques para producir, en última instancia, 'un proceso activo de inclusión del trabajo migrante a través de su ilegalización'. Esto conlleva un proceso de inclusión diferencial, en el que la irregularidad aparece como una condición producida y como un aspecto clave en la política de movilidad (Mezzadra, 2012, p. 171).

De ese modo, este régimen resulta funcional al papel que desempeña la migración internacional en la economía global contemporánea, en la medida que opera estableciendo un acceso desigual a la movilidad de las personas: mientras que algunas formas de desplazamiento son alentadas (por ejemplo, las llamadas "migraciones calificadas", o aquellas ligadas a la operación de las empresas transnacionales), otras son restringidas.

La ilegalización de los desplazamientos a la que alude este autor es uno de los principales mecanismos de este régimen para establecer jerarquías en el acceso a la movilidad a partir de la figura de la irregularidad (De Genova, 2002), que termina por instituirse como una característica del propio migrante, cuando en realidad es una construcción del Estado receptor, a partir de una compleja trama de acciones e inacciones. Así, entonces, se introduce otra dimensión de estratificación de los trabajadores, que se intersecta de modos complejos y variables con la clase, el género, la etnia, la "raza", la sexualidad, la generación, etc. (Bauman, 2003; Kalm, 2008).

Ahora bien, mientras las políticas de control mediante las que opera la ilegalización jerarquizan y determinan geopolíticamente la movilidad, en paralelo se valoriza la 
migración desde una retórica de derechos (Domenech, 2013). Se apela entonces a un tipo de discurso que permite lograr de manera más eficaz y legitimada aquello a lo que se apunta: regular y filtrar las movilidades de modo funcional, o lo que también se ha llamado las "políticas de control con rostro humano" (Domenech, 2013). Esta apelación a la retórica de los derechos humanos para legitimar políticas de control de las migraciones es una de las características centrales del paradigma de la gobernabilidad migratoria, entendida desde una aproximación crítica como la versión latinoamericana del migration management (Domenech, 2018), que para la OIM, organismo internacional que representa uno de sus principales artífices, es

un término general que refiere a la gama de medidas necesarias para abordar efectivamente las cuestiones de migración a nivel nacional, regional y mundial. Abarca las políticas, la legislación y la administración de los asuntos de la migración y contribuye a la buena gobernanza (OIM, 2003, p. 53, énfasis propio).

En su versión sudamericana, la gobernabilidad migratoria ha sido definida como "la posibilidad de los gobiernos de conciliar las características, causas y efectos de los movimientos migratorios con las expectativas y demandas sociales sobre los mismos, y las posibilidades reales de los Estados para darles respuestas" (Mármora, 2003, p. 119).

Desde una aproximación crítica -que es la que adoptamos en este artículo-, las políticas migratorias sustentadas en el paradigma o enfoque de la gobernabilidad migratoria se caracterizan por una serie de aspectos que Domenech (2018) ha sistematizado a partir de su trabajo: una mirada del gobierno de las migraciones sustentado en las ideas de "administración, gestión o gerenciamiento"; la noción de "apertura regulada" del país a la entrada de migrantes; la premisa central de la "migración ordenada", ligada a la construcción de la migración irregular-ilegal como problema mundial que acarrea riesgos que deben prevenirse y combatirse; una implementación articulada regional y globalmente, y basada en mecanismos multilaterales y de cooperación; la lógica costobeneficio para pensar las migraciones, bajo la idea de minimizar los primeros y maximizar los segundos, asumiendo que, correctamente "administradas", las migraciones suponen ganancias para todos los actores involucrados; la división entre flujos deseables y no deseables según su carácter ordenado/desordenado, voluntario/forzoso y reducido/masivo; el hecho que "contempla los derechos humanos de los migrantes, subordinados a la administración eficaz de los flujos migratorios, y apela al discurso 'humanitario', en ocasiones movilizando la idea del migrante como "víctima"”; y "el esquema de control subyacente [que] implica prácticas de gobierno orientadas al direccionamiento, canalización o encauzamiento de los flujos migratorios, antes que estar inspirado en nociones abiertamente restrictivas de las fronteras o imágenes criminalizantes de la migración" (Domenech, 2018, p. 112-113). 


\section{Aspectos metodológicos}

Para abordar este problema de investigación se recurrió a una aproximación metodológica cualitativa, más concretamente, al análisis documental, desde la perspectiva del análisis crítico del discurso, entendiendo al discurso, según Ernesto Laclau y Chantal Mouffe, como el conjunto sistemático de relaciones construidas socialmente (Laclau y Mouffe, 1987, p. 109) ${ }^{4}$, partiendo de la premisa de que toda configuración social es una configuración significativa. Según la perspectiva de estos autores, el discurso social, en tanto que sistema de identidades diferenciales, existe en la forma de una limitación parcial a un exceso de sentido que lo perturba, el campo de la discursividad. Esa limitación parcial de la significación se realiza a través de un proceso de articulación, que logra estabilizar algunos significantes flotantes mediante la fijación contingente de puntos nodales, a partir de un enfrentamiento inestable entre prácticas hegemónicas y antagónicas. El discurso social es, entonces, "la totalidad estructurada resultante de la práctica articulatoria” (Laclau y Mouffe, 1987, p. 119). El trabajo de análisis del corpus discursivo delimitado buscó, por lo tanto, determinar esos puntos nodales, siguiendo una lógica hipotético-deductiva, que partió de una formulación inferencial derivada del enfoque teórico crítico respecto de la gobernabilidad de las migraciones adoptado. Concretamente, y a partir de un trabajo previo que ha buscado explorar el pensamiento del Estado chileno respecto de la migración internacional desde la dictadura cívico-militar -1973 en adelante- (Stang, 2016; Stang, 2020), se parte de la hipótesis según la cual este programa es una cristalización de la específica apropiación del enfoque de la gobernabilidad de las migraciones que ha realizado el Estado chileno, al menos, desde el 2000 en adelante, y que ha persistido, con particularidades, tanto en gobiernos de signo ideológico de derecha como de izquierda.

En este contexto, se ha entendido por corpus, según la interpretación deleuziana de Foucault, un conjunto de frases y textos del que es posible extraer enunciados (Deleuze, 1991). Por enunciado, a su vez, se alude a "cada momento del discurso en su irrupción de acontecimiento, en esta puntualidad en que aparece, y en esta disposición temporal que le permite ser repetido, sabido, olvidado, transformado" (Foucault, 1983, p. 96). Se trata de "la modalidad de existencia de un conjunto de signos, ...que le posibilita ser algo más que un simple conjunto de marcas materiales: referirse a objetos y a sujetos, entrar en relación con otras formulaciones y ser repetible" (Castro, 2004). El enunciado es, por lo tanto, mucho más que una oración, una frase, o una cita referida a un tópico determinado; es la irrupción histórica - material y contextualizada- del discurso social a partir de un acto de enunciación que permite coagular en la superficie textual ciertas densidades significantes

4 Esta postura frente al discurso supone concebirlo como una totalidad que incluye tanto a lo lingüístico como a lo extralingüístico: "la práctica de la articulación como fijación/dislocación de un sistema de diferencias [no] puede consistir en meros fenómenos lingüísticos, sino que debe atravesar todo el espesor material de las instituciones, rituales, prácticas de diverso orden, a través de las cuales una formación discursiva se estructura" (Laclau y Mouffe, 1987, p. 125). 
construidas socialmente en ese tiempo y espacio que determinan las coordenadas que permiten la emergencia de ese sujeto de la enunciación.

Este corpus de análisis estuvo compuesto por textos oficiales de diverso tipo (oficios, circulares, minutas) y notas de prensa, vinculados todos a las medidas recientes que son objeto de análisis en el artículo, además de otros textos oficiales de carácter normativo, discursos de autoridades y funcionarios y notas de prensa que acompañaron los anuncios e implementaciones de esos proyectos o normas, estos últimos referidos a hitos en el proceso de cristalización del pensamiento de Estado sobre migración internacional en Chile 5 . Aunque el análisis detallado de este segundo grupo de textos del corpus ocupa un espacio reducido del artículo, por razones de espacio, está en la base de los argumentos que se presentan, y fue central para observar la densidad en torno a los puntos nodales identificados, coincidentes en gran medida con los elementos definitorios del paradigma de la gobernabilidad migratoria sistematizados por Domenech (2018), y detallados en el apartado previo.

Para complementar este análisis se realizaron entrevistas semi-estructuradas a informantes clave consultados en su calidad de expertos -representantes de organizaciones de la comunidad haitiana en Chile (2), miembros de clínicas jurídicas y organismos judiciales con atención a migrantes (2), de organizaciones de y para migrantes (3)-. La selección de estos informantes obedeció centralmente a dos criterios: su conocimiento jurídico en torno a los temas de migración y extranjería, para entender esta arista de las medidas, y su conocimiento del proceso de implementación del programa en cuestión, por su trabajo en terreno y contacto con migrantes haitianos. También se consideraron presentaciones públicas de funcionarios del gobierno vinculados a los temas migratorios ${ }^{6}$, como apropiaciones enunciativas del pensamiento estatal sobre migraciones cristalizado en los documentos asociados a este programa.

5 Se trata del proyecto $N^{\circ}$ 2891, de modificación del DL 1094 de 1975 (que Establece Normas sobre Extranjeros en Chile), de 1993 (presidencia de Patricio Aylwin, 1990-1994); el instructivo presidencial sobre Política Nacional Migratoria de 2008 (primer período presidencial de Michelle Bachelet, 20062010); el documento 005 del Gabinete Presidencial "Lineamientos e Instrucciones para la Política Nacional Migratoria sobre Política Nacional Migratoria" de 2015, y el Proyecto de Ley de Migraciones $\mathrm{N}^{\circ}$ 124-365, de 2017 (segundo período presidencial de Michelle Bachelet, 2014-2018), y finalmente el Proyecto de Ley de Migración y Extranjería No 089-361, presentado en 2013, durante el primer gobierno de Sebastián Piñera (2010-2014), y reflotado con algunas modificaciones durante su segundo mandato, en abril de 2018.

6 Fueron infructuosos los intentos por lograr entrevistas con funcionarios del Departamento de Extranjería y Migración (DEM) y la Subsecretaría de Interior del Ministerio del Interior y Seguridad Pública, de quien depende el DEM. 


\section{Medidas recientes respecto de la migración haitiana en Chile}

Las medidas que apuntan a restringir en alguna forma la llegada de migrantes haitianos a Chile no son estrictamente novedosas. En efecto, desde 2012, durante la primera gestión presidencial de Sebastián Piñera (2010-2014), se impuso la exigencia informal de una carta de invitación y mil dólares para ingresar al país, con un consecuente aumento del rechazo en frontera (Rojas Pedemonte et al., 2017). Sin embargo, las medidas implementadas durante 2018 respecto de este grupo nacional, aunque fundadas en argumentos humanitarios, adoptaron una posición más claramente restrictiva y expulsiva, que tienen que leerse a la luz de un escenario más amplio, tanto a escala nacional como regional. En el primer caso, ese escenario abarca un plan de regularización extraordinaria ${ }^{7}$, la reactivación de un proyecto de reforma de la ley de migraciones, y la creación de algunos tipos de visa por vía administrativa que anunciaban la orientación tanto del proyecto de ley que avanza en el parlamento como de la política migratoria en general: una mirada selectiva de las migraciones, de corte utilitarista y securitista, que recurre al discurso de los derechos humanos como fundamento, pero que los reconoce de modo parcial y condicionado, con amplios espacios para la arbitrariedad en su garantía (Stang, 2016).

El análisis detallado de todas estas medidas excede los alcances de este artículo, de todos modos, es necesario considerar el Plan Humanitario de Regreso Ordenado en su relación con las otras acciones implementadas específicamente respecto de la población haitiana: la Visa Consular de Turismo Simple para ingresar al país y la Visa Humanitaria de Reunificación Familiar.

La visa consular, establecida mediante Decreto en abril de $2018^{8}$, fija dicho requisito para el ingreso al país y la permanencia por hasta 90 días "con fines de recreo, deportivos, religiosos u otros similares", pero sin propósito de inmigración, residencia o desarrollo de actividades remuneradas. La medida se funda en el "interés nacional [de] dotar al país de una migración ordenada, segura y regular", en el "aumento sostenido de ciudadanos de origen haitiano que ingresan al país con fines declarados de turismo pero permanecen en Chile en situación irregular", lo que según el decreto "expone a los migrantes y a sus familias a ser objeto de redes de tráfico de personas y a otros riesgos derivados de su

7 Esta medida en particular resulta en apariencia disruptiva con la enumeración en su conjunto, dado que supuestamente apunta a beneficiar a los migrantes. Sin ánimo de poner en duda la incidencia positiva de esta acción en la vida cotidiana de los migrantes, lo cierto es que, al tratarse de una medida excepcional, cubre la regularidad del migrante de esa misma condición de excepcionalidad, y termina vinculando su permanencia "legal" a la idea de moratoria o "perdonazo". Por otra parte, como observa Domenech, "el carácter invariablemente parcial de los procesos de 'legalización' o 'regularización' nunca elimina el campo de la 'ilegalidad', sino que más bien refina y reconstituye ese campo para los que no resultan elegibles y permanecen indocumentados a la par de todas las posteriores llegadas 'ilegales" (Domenech, 2017, p. 32-33).

8 Decreto No776 (17/04/2018), Ministerio del Interior y Seguridad Pública, Establece visto consular de turismo a nacionales de Haití. 
situación irregular", y en que este panorama exigiría "una gestión integral que tienda a la gobernabilidad migratoria, permanencia regular en el país, protección al migrante y ejercicio pleno del estado de derecho" (Decreto 776, énfasis propios).

En paralelo, se creó un Visado Humanitario de Reunificación Familiar para los cónyuges, convivientes civiles, hijos menores de edad y mayores que estudien hasta los 24 años de aquellos migrantes haitianos que no poseyeran antecedentes penales, de 12 meses de duración y prorrogable por una vez, con un máximo anual de 10 mil visados humanitarios, que solo se pueden solicitar en el consulado chileno en Haití. Ambas medidas, como se ve, responden a una lógica de desterritorialización del control y del filtro migratorio, que se desplazan hacia el país de origen (Trabalón, 2018). Los expertos entrevistados coinciden en señalar que todas las dificultades asociadas a la tramitación de estos visados han significado una gran barrera para su obtención, como lo confirman las cifras citadas en la introducción. La línea de argumentación seguida por el Ministerio del Interior y Seguridad Pública, de quien depende el tema migratorio en el país, ha sido la de poner énfasis en la "ilegalidad" que supone el ingreso como turista cuando los fines serían otros, y el "negocio étnico" generado por una red de tráfico de estos migrantes, de la que supuestamente se buscaría protegerlos:

...había un negocio étnico, y el negocio étnico es: 'venda todo lo que tiene en su país, consígase dinero, pague y véngase a Chile, porque en Chile se va a poder regularizar, en Chile va a encontrar empleo fácilmente, entonces le vende a la persona y básicamente la trafica. Hay 17 querellas, muchas de esas víctimas fueron haitianos, y eso es algo que tenemos que mirar. No es tan simple como decir que poner un visado discriminó, no, poner un visado lo que hizo fue ordenar (exposición de asesor de migraciones del Ministerio del Interior, 11/3/2019) ${ }^{9}$.

Así, la protección del migrante por su propia "vulnerabilidad" ante las redes de tráfico, y la ilegalidad que se les atribuye, como una condición a la que se le confiere carácter volitivo, se utilizan como fundamentos de medidas que en la práctica restringen la llegada de estos migrantes, en tanto que interponen una barrera administrativa en el propio país de origen.

La tercera medida adoptada por el gobierno chileno, al poco tiempo de asumida una nueva gestión, que implícitamente se dirigió a este grupo nacional, fue el ya mencionado "Plan Humanitario de Regreso Ordenado". En términos explícitos está dirigido a extranjeros, tanto en condición regular como irregular, e incluso en situación de refugio, que decidan retornar voluntariamente a su país de origen, de forma individual o como grupo familiar. Concretamente, se hace cargo de su traslado gratuito al país de su nacionalidad, a condición de cumplir ciertos requisitos: tener documentos de viaje válidos y vigentes; adoptar "de manera libre y voluntaria" la decisión de retornar; no tener impedimentos legales para salir

9 Realizada en el marco del Seminario "Migración, inclusión y desarrollo: una mirada de futuro", en la sede de Santiago del Congreso Nacional. 
del territorio nacional; comprometerse "libre y voluntariamente" a no regresar a Chile; renunciar a las solicitudes de visa y refugio vigentes, entre los más importantes.

Volveremos sobre esta medida para un análisis más detallado, pero como señalamos al iniciar el apartado, estas medidas necesitan leerse en un escenario más amplio, no solo nacional, sino también a escala sudamericana, al menos. En ese sentido, dicho Plan de retorno, especialmente dirigido a los migrantes haitianos residentes en Chile, y las visas consulares establecidas respecto de este mismo grupo nacional, no son una acción de política pública aislada. Entender este escenario es un aspecto importante de la propuesta analítica de este artículo.

\section{Regionalización de las medidas de gestión/control de la migración haitiana}

En los últimos años se han ido entretejiendo diferentes tipos de barreras a la movilidad de los migrantes haitianos en Sudamérica, como reacción a su creciente desplazamiento hacia algunos países de destino (o de tránsito) del subcontinente, sobre todo con posterioridad al terremoto que sufrió Haití en 2010, un acontecimiento que varios autores que se han ocupado de estas migraciones consideran un hito para estos procesos en su redireccionamiento hacia algunos destinos sudamericanos (Nieto, 2014; Cejas, 2015; Trabalón, 2018). Un repaso breve de este proceso permite observar los vínculos entre ciertos mecanismos de fronterización, la forma en que van incidiendo en los recorridos que realizan los migrantes, que toman la forma de "estrategias de contorneamiento" (Mallimaci y Pedone, 2019), y la coincidencia y articulación de estas medidas en lo que se ha denominado una regionalización de la política migratoria (Domenech, 2015) ${ }^{10}$.

En un trabajo reciente, Trabalón (2018) realiza un abordaje detallado de este tema a partir del relevamiento de las medidas adoptadas en los últimos años respecto de los haitianos en Brasil, Chile y Argentina como destinos, además de Perú y Ecuador como países de tránsito, demostrando cómo este grupo nacional ha sido incorporado a la agenda de seguridad mediante prácticas estatales selectivas, transformando a la política de visado en un mecanismo fundamental de regulación de los movimientos migratorios, un mecanismo

10 Aunque el marco espacial de este análisis es Sudamérica, aporta a estos argumentos el señalamiento de medidas tomadas por los Estados Unidos respecto de los migrantes haitianos en este período, y que apuntan en el mismo sentido que las que se describen en este apartado. Después de 2010, a causa del terremoto que experimentó Haití, Estados Unidos suspendió las deportaciones de personas de este origen, pero en 2016 el presidente Obama anunció que se reanudarían las deportaciones de migrantes haitianos "indocumentados" (https://www.nytimes.com/es/2016/09/23/espanol/estados-unidos-aumenta-de-manerainesperada-las-deportaciones-de-haitianos.html). Al año siguiente el presidente Trump, por su parte, anunció el final de un programa migratorio especial que evitaba la deportación de miles de haitianos del país (https://elpais.com/internacional/2017/11/21/estados_unidos/1511228841_138087.html). Se trataba del programa de Estatus de Protección Temporal, creado en 1990, que permitía al país conceder visados extraordinarios a ciudadanos afectados por guerras o desastres naturales. 
que además "pone en evidencia la persistencia del origen nacional como principio de selección fundamental de las poblaciones móviles" (Trabalón, 2018, p. 165).

Tras el terremoto de 2010 en Haití, algunos Estados sudamericanos -concretamente Brasil, Ecuador, Venezuela y Chile- tomaron medidas tendientes a facilitar la regularización de los ciudadanos haitianos que residían en sus territorios y la reunificación con sus familias, como un gesto de solidaridad. Pero a poco andar, y ante el incremento de esta corriente migratoria hacia el subcontinente, empezaron a surgir las acciones restrictivas (Nieto, 2014).

En el caso de Brasil, se decidió en principio el otorgamiento de residencias permanentes por razones humanitarias a los haitianos que ya se encontraban en el país, en marzo de 2011. En enero de 2012 se permitió la emisión de visas humanitarias en el consulado de Brasil en Puerto Príncipe, fijando un cupo de 100 visas por mes durante 5 años, cupo que se eliminó en abril de 2013, agregando la posibilidad de realizar el trámite en Ecuador, Bolivia y República Dominicana, como respuesta a la gran demanda y las dificultades que acarreaba la realización de la gestión solamente en Puerto Príncipe (Trabalón, 2018; IPPDH y OIM, 2017).

Por otra parte, como Ecuador había eliminado en 2008 las visas de ingreso para los haitianos, se fue convirtiendo en un país de tránsito en el mapa migratorio de este grupo nacional -y progresivamente también en destino-. En febrero de 2010 el Estado ecuatoriano comenzó a entregar visas humanitarias por 5 años a los haitianos que hubieran entrado en el país antes del 31 de enero de 2010 (Cejas, 2015). La llegada creció entonces significativamente, y en paralelo aumentaron las prácticas de rechazo en frontera en los aeropuertos. En agosto de 2015 se implementó la exigencia de una solicitud de permiso sujeta a evaluación a través del "Sistema Virtual de Registro Turístico” (Trabalón, 2018).

Perú también se había convertido en una ruta de ingreso a Brasil para los ciudadanos haitianos, pero en enero de 2012 se les empezó a solicitar visa de turismo, debido a la presión del gobierno brasilero “en el marco de 'procesos de cooperación' entre Brasil y los países considerados de tránsito hacia Brasil" (Trabalón, 2018, p. 168). Como señalan varios autores, esta restricción no disminuyó el ingreso, pero sí incidió en el aumento de la irregularidad (Nieto, 2014; Cejas, 2015), como sucede habitualmente en estas circunstancias.

El funcionamiento conjunto de las medidas tomadas por estos tres países (Brasil como destino, y Ecuador y Perú de tránsito, en principio) fueron configurando un escenario de irregularidad-precariedad para los migrantes haitianos, al que se iba respondiendo con medidas selectivas y restrictivas ${ }^{11}$. Así,

11 Para una descripción más detallada de este escenario, véase Trabalón (2018). 
el visado humanitario, se configuró como una práctica más de control migratorio y fronterizo que, con el objetivo de desterritorializar el control hacia los consulados en origen, supuso la puesta en marcha de dispositivos de 'gestión' o regulación de las movilidades que reafirman la posición del Estado como productor de la irregularidad migratoria (Trabalón, 2018, p. 169).

Argentina, a diferencia de los países anteriores -y de Chile-, no fue en lo inmediato un destino importante de esta población con posterioridad al terremoto de 2010, sino que comenzó a aparecer más claramente en el mapa migratorio haitiano hacia Sudamérica alrededor del 2015. En ese contexto, desde 2017 han aumentado los rechazos de migrantes haitianos en frontera, apelando a la categoría del "falso turista" (Trabalón, 2018).

Esta figura, implementada mediante una Disposición de la Dirección Nacional de Migración (DNM) de 2014, estipula la documentación que debe requerir el agente de frontera a la persona que buscara ingresar al territorio nacional "cuando hubiese duda respecto de la real intención del extranjero, en tanto que esta pudiera diferir del propósito de turismo". La medida se relaciona con el hecho de que en Argentina el ingreso como turista "es generalmente el primer escalón para luego acceder a otra categoría de residencia dentro del país, en la medida en que no hay restricciones para este tránsito categorial excepto el pago de un monto de dinero-" (Thayer, Stang y Abarca, 2017, p. 32).

Con este panorama, en mayo de 2018 la DNM emitió un memorándum exigiendo la aplicación de la figura del "falso turista" a los migrantes haitianos y de "otras nacionalidades sensibles", explicando en notas periodísticas que la medida obedecía a la necesidad de “"regular el ingreso' de inmigrantes haitianos ante el aumento del número que llegaba al país sin encuadrar en la categoría de turista” (Trabalón, 2018, p. 172).

El análisis de los casos nacionales que realiza Trabalón (2018) permite observar, por una parte, cómo se van reorientando las rutas migratorias en respuesta a las medidas restrictivas que implementan los Estados, y por la otra, cómo se recurre a argumentos humanitarios para justificar esas decisiones restrictivas, lo que nos interpela a pensar las medidas tomadas en Chile en relación con este escenario mayor, y a procurar entender cuál es el hilo que conecta estas similitudes.

\section{$5 \quad$ El Plan de regreso ordenado y sus argumentos humanitarios}

Descrito el marco nacional y regional de las medidas adoptadas respecto de la migración haitiana, se analiza en este apartado el Plan humanitario de regreso ordenado, desde una aproximación sociopolítica y jurídica, a partir de tres elementos que consideramos centrales para explorar el sustento de su argumento humanitario y de derechos humanos: el supuesto "fracaso" en la integración, causal de la situación de vulnerabilidad a la que en teoría se pretende responder; la ausencia de consideración de las condiciones para el retorno, y la 
supuesta voluntariedad de la adhesión al Plan, aspecto específico en el que se concentra el abordaje jurídico.

En los fundamentos del Plan se sostiene explícitamente que la medida está sustentada en el enfoque de la gobernabilidad migratoria, en la búsqueda de una migración ordenada, segura y regular, y en la atención a la situación de vulnerabilidad que experimentan cierto tipo de migrantes. Aunque la categoría de "migrante vulnerable" es construida por el propio Estado, este argumento resulta muy convincente respecto de ciertas circunstancias experimentadas por la población haitiana en Chile.

En un informe del Departamento de Extranjería y Migración sobre dicho grupo nacional se señala, en relación con sus procesos de inserción en la sociedad chilena, que la migración haitiana se caracteriza transversalmente por "la exclusión sociocultural, marcada por el racismo" (DEM, 2016, p. 10). Ello se materializa, por ejemplo, en los procesos de inserción laboral, que se realizan principalmente en trabajos precarios y de baja calificación (IPPDH y OIM, 2017; DEM, 2016): "suelen ocupar puestos poco valorados, mal remunerados, con altos niveles de riesgo y una carga laboral a veces abusiva" (DEM, 2016, p. 10). A ello se suma el desaprovechamiento de las capacidades de los profesionales, en la medida que no se reconoce su formación, "ni social ni formalmente” (DEM, 2016, p. 10).

Por otra parte, como señala el informe del DEM, la diferencia de idioma opera como una barrera en los procesos de inserción de la población haitiana en Chile, tanto en la búsqueda de trabajo como "en la defensa de sus derechos frente a los abusos laborales que describen en las entrevistas" (DEM, 2016, p. 10), además de otros ámbitos. Otro aspecto que se identifica como crítico o problemático en la inserción de este colectivo es el relativo a la vivienda: "El trabajo de terreno develó los importantes niveles de hacinamiento a los que están confrontados los migrantes haitianos y las malas condiciones en la que están obligados a vivir" (DEM, 2016, p. 10), especialmente en la Región Metropolitana.

Con esos antecedentes, el argumento relativo de la preocupación por la vulnerabilidad de estos migrantes resulta verosímil y, en consecuencia, está legitimada. Es esa preocupación la que permite presentar la medida como una respuesta de política desde un abordaje humanitario y de derechos humanos, es decir, se recurre a esa vulnerabilidad, y al sufrimiento social que ella puede implicar, como base para argumentos morales que operan como justificaciones de las medidas de política que han tenido en la práctica un carácter restrictivo y expulsor. Así, direccionando el abordaje al ámbito de la moral, se invisibilizan los aspectos históricos y estructurales que explican los procesos sociales sobre los que se busca intervenir (Pacecca, 2018), entre ellos, el racismo estructural que afecta a la población migrante afrodescendiente en Chile (Tijoux, 2016; Stang y Stefoni, 2016), entre otros aspectos. 
Desde esta lógica, en los considerandos de la Resolución que establece el Plan se señala que:

se hace indispensable atender a la situación planteada por las comunidades migrantes de aquellas personas que se encuentran en situación de vulnerabilidad, por no haber logrado una eficaz integración, sustentabilidad o regularidad en el país, por razones laborales, idiomáticas, socioculturales o por no poder cumplir con los requisitos establecidos para acceder a los diferentes medios de regularización ordinaria o extraordinaria (énfasis propio) (Resolución Núm. 5.744 exenta, 2018, p. 1).

Como se lee, el argumento de la Resolución coloca en el propio migrante la responsabilidad por la situación de vulnerabilidad en la que se encuentra, puesto que no fue capaz de lograr "una eficaz integración, sustentabilidad o regularidad en el país" (Resolución Núm. 5.744 exenta, 2018, p. 1), ya sea por su lengua, por sus características socioculturales, porque no encontró trabajo, o no cumplió los requisitos que el Estado le puso para acceder a la regularidad. Como explica Gil Araujo (2010), la integración, planteada en clave de racionalidad liberal avanzada, se piensa como un camino de provisión de "herramientas, habilidades y aptitudes de integrabilidad"; entonces, si el migrante fracasa en ese camino, en esta lógica, se debe a su falta de disposiciones para ello (por sus características y diferencias); la integración, de ese modo, dependería de su voluntad. Desde este punto de vista, el carácter humanitario se utilizaría para diluir la responsabilidad del Estado por la generación de políticas que hubiesen procurado subsanar esas dificultades a las que se alude.

Otra arista que, según el análisis propuesto, evidencia la artificiosidad del carácter humanitario del Plan, es el hecho que no ha considerado ninguna medida para acompañar el retorno de los migrantes al país de origen, un aspecto crucial según los estándares internacionales en esta materia. Aun cuando no existe un marco jurídico internacional en relación con las condiciones en que se deben realizar los planes de retorno, la OIM ha elaborado un estándar de referencia para el diseño de "Planes de retorno y reintegración asistidos y voluntarios" (AVRR) (IOM, 2018) ${ }^{12}$. Según este estándar, un elemento indispensable de estos planes es la necesidad de atender a la sostenibilidad de la reintegración, con lo que se alude a la suficiencia económica, la estabilidad social dentro de sus comunidades y el bienestar psicosocial en el país al que se retorna. Varios de los actores entrevistados para este estudio, tanto expertos en derecho como miembros de organizaciones de y para migrantes, señalan la ausencia de consideración de esta fase del Plan:

12 De hecho, resulta paradojal que no se lo hubiese tenido en cuenta en el diseño del Plan, cuando en los considerandos de la propia Resolución que lo crea se señala a la OIM como sustento de la medida, al sostener que "según indica la Organización Internacional para las Migraciones -OIM-, los retornos voluntarios asistidos y las estrategias de reintegración de migrantes son elementos indispensables en una perspectiva global de gobernanza de la migración". 
Cualquiera de los planes de retorno que hicieron los organismos internacionales tienen en cuenta la reinserción de las personas en los países a los cuales se dirigen, y se acuerda con los gobiernos, esto no fue acordado con el gobierno de Haití... Lo único que se les da a las personas es la llevada en avión... (...) ¿Pero a dónde llegan? Llegan a la misma situación de la que partieron, pero derrotados. La gente llega con más vulnerabilidad, incluso psicológica, incluso de resiliencia, que cuando salió, y eso tiene consecuencias. Y una de las consecuencias de que nos enteramos, del caso que te conté, de este chico haitiano que llegó, vio a su familia y al otro día se suicidó (entrevista a miembro de organización de migrantes, 17/1/2019).

...muchos haitianos creen o pensaban que el Plan de Retorno les van a pasar algo de dinero para regresar a su país, algunos pensaban eso. Pero no, el Plan de Retorno no contemplaba eso (entrevista a miembro de comunidad haitiana, 16/3/2019).

Esta ausencia de previsión respecto de las condiciones en las que se retorna, y de las posibilidades reales de reinserción del migrante retornado, es otro de los aspectos que debilita el argumento humanitario y de derechos humanos del Plan. ¿En qué medida se sustenta la preocupación por las condiciones de vulnerabilidad de estos migrantes, si esa preocupación se diluye al cruzar la frontera? y más aún, como se señalaba respecto del primer punto de objeción (el "fracaso" de la integración), ¿en qué forma se sostiene esta preocupación que anima el Plan, si la medida no busca solucionar el problema en Chile, solo eliminarlo a partir del traslado?

El último de los principales puntos endebles de esta argumentación humanitaria es la supuesta voluntariedad de la decisión de retorno. En efecto, uno de los requisitos para "beneficiarse" con el plan es, como vimos, que la decisión de retornar al país de origen se adopte de manera libre y voluntaria. Para los actores entrevistados, este supuesto carácter voluntario es puesto en entredicho por dos razones principalmente: por el grado de "libertad" de decisión que se pueda tener en condiciones de precariedad, como las que experimentan muchos migrantes haitianos en Chile, y por otro requisito que se establece para postular: el compromiso de no retornar a Chile por al menos 9 años, acreditado mediante un documento notarial.

Uno de los principios centrales que debiera cumplir un plan de retorno, según el marco de referencia de la OIM al que se ha aludido, es precisamente la voluntariedad, que se asume que existe cuando se dan dos condiciones: 1) libertad para escoger, lo cual implica ausencia de presiones físicas o psicológicas por retornar, y 2) una decisión informada, lo que requiere la disponibilidad de información oportuna, imparcial y confiable sobre la cual basar la decisión. El cumplimiento de esta segunda exigencia se ha puesto en duda en este caso, por la diferencia idiomática de la población haitiana, y por la desinformación observada en los postulantes, referida por miembros de organizaciones de y para migrantes, y de clínicas jurídicas, que siguieron de cerca el proceso de implementación. La libertad para escoger, en tanto, se ha cuestionado, por una parte, por las dificultades de inserción 
efectiva que ha enfrentado la población haitiana en Chile, traducidas principalmente en situaciones de precarización y marginalización socioeconómica, y por la otra, por la duración de la exigencia de no retorno, este lapso de 9 años.

Respecto de la coacción que supone la precarización, uno de los actores clave entrevistados expresó de manera clara la fragilidad del argumento de la voluntariedad: “¿Cómo puede ser libre el consentimiento prestado por personas extranjeras que se encuentran en una situación personal, social y económica dramática?" (entrevista a abogado ex miembro de organismo judicial con atención de casos de migrantes, 27/2/2019). Otro experto en derecho coincide con el señalamiento:

El Estado chileno limitó el acceso a derechos sociales [de la población haitiana]. No hubo proceso de integración en Chile. No es voluntario porque les dan a elegir a quienes están entre la espada y pared. Así no tienen opciones de elegir (entrevista a abogado miembro de organización para migrantes, 21/3/19).

En el segundo caso, el supuesto carácter voluntario también es puesto en entredicho por la prohibición de reingreso a Chile por 9 años. Como señala una abogada de una clínica jurídica entrevistada: "Prohibición por nueve años y voluntario es una contradicción de términos". Los actores entrevistados ponen atención en esta cantidad de años que se establecen en la prohibición, sobre todo por la relevancia de este argumento para la consideración del Plan como una medida de expulsión o deportación indirecta, y selectiva, que es la opinión en la que coinciden varios de ellos. Por esa importancia, el próximo apartado se detiene en un análisis jurídico de este aspecto.

\subsection{El Plan a la luz del análisis jurídico}

En general, la expulsión de extranjeros puede ser conceptuada "como una salida coactiva del territorio nacional acompañada de la prohibición temporal de entrada en él" (Muñoz Ruiz, 2014:05:7). Según el derecho internacional de los derechos humanos, la regulación estatal de las expulsiones se debe sujetar a ciertos límites. La práctica jurídica de las expulsiones que contempla el derecho chileno, valorada a partir de estos límites, es cuestionable desde varios aspectos, cuyo detalle excede los límites de este artículo.

Por su relevancia para el análisis del Plan en que se focaliza este trabajo, y para la calificación de esa medida como una expulsión/deportación indirecta y selectiva, la exposición se detendrá en este apartado en el lapso de 9 años estipulado para el impedimento de retorno. Ello supone describir muy brevemente los mecanismos de expulsión de extranjeros en la legislación chilena, con el fin de compararlos con el Plan y mostrar de qué manera, a pesar de su carácter supuestamente voluntario, constituye una amenaza para los derechos humanos de los extranjeros en Chile y, por ende, pone en cuestión la retórica humanitaria y de derechos a la que se ha recurrido para sustentarlo. 
En Chile coexisten dos regímenes de expulsión de extranjeros: el penal y el administrativo. En el primero pueden distinguirse tres posibilidades: la primera es el caso en que un extranjero cometiera un delito en el territorio nacional y fuera condenado a una pena igual o inferior a cinco años de presidio o reclusión menor en su grado máximo. En esta situación, “el juez, de oficio o a petición de parte, podrá sustituir el cumplimiento de dicha pena por la expulsión de aquél del territorio nacional" (artículo 34, Ley 18.216) ${ }^{13}$ cuando se trata de delitos cometidos por extranjeros que no cuentan con residencia legal. Las otras dos posibilidades en el régimen penal están contempladas en el Decreto Ley (DL) 1094 (1975), que "Establece normas sobre extranjeros en Chile", y su reglamento, el Decreto Supremo (DS) 597 del Ministerio del Interior.

A pesar de tratarse de legislación administrativa, estos decretos contemplan disposiciones de naturaleza penal: una para los extranjeros que ingresen o egresen del país mediante "documentos falsificados, adulterados o expedidos a nombre de otra persona o hagan uso de ellos durante su residencia" (artículo 68 DL 1094), estableciendo una pena de presidio menor en su grado máximo (3 años y 1 día a 5 años), con accesoria de expulsión una vez cumplida la pena; la otra sanciona a los extranjeros que ingresen o egresen del país clandestinamente, es decir, "cuando se burle en cualquier forma el control policial de entrada" (artículo 69 del DL 1094), estableciendo una pena de presidio menor en su grado máximo (3 años y 1 día a 5 años); si lo hicieran por lugares no habilitados, la pena es de presidio menor en sus grados mínimo a máximo (de 61 días a 540 días hasta 3 años y 1 día a 5 años), y si lo hicieran por lugares no habilitados o clandestinos existiendo además impedimento o prohibición de ingreso, de presidio menor en su grado máximo a presidio mayor en su grado mínimo (de 3 años y 1 día a 5 años hasta 5 años y 1 día a 10 años); en todos los casos se aplica la expulsión una vez cumplida la pena.

En el régimen administrativo, la expulsión es una sanción por alguna infracción, como permanecer en Chile con permisos vencidos, obtener visación mediante simulación o fraude en la celebración del contrato de trabajo, y por infracciones graves o reiteradas al deber de registrarse, obtener cédula de identidad, comunicar a la autoridad el cambio de su domicilio o actividad, desarrollar actividades remuneradas sin autorización, y en el caso de asilados políticos, realizar actividades que, en forma directa o indirecta, puedan significar una acción contraria al gobierno de su país (artículos 62, 67, 70, 71, 72 y 154 del DL 1094).

Tanto el régimen penal como el administrativo contemplan la prohibición de regreso al territorio nacional como consecuencia de la expulsión, y salvo en el caso en que se establece como pena sustitutiva por delitos comunes, ese plazo es indefinido ${ }^{14}$. En esta

13 Esta norma fue modificada por la Ley 20.603, que establece penas que indica como sustitutivas a las penas privativas o restrictivas de libertad.

14 Así lo ha establecido la Contraloría General de la República, en el Dictamen № 025128N14 del 9 de abril de 2014. De todos modos, como señala el artículo 84 del DL 1094, esas prohibiciones "podrán ser revocadas o suspendidas temporalmente en cualquier momento". La Corte Suprema ha compartido ese criterio en un caso reciente, la Causa Rol No 80259-2018, del 3 de enero de 2019. Se trata de un recurso de 
excepción, sí se estipula la cuantía del plazo: "El condenado extranjero al que se le aplicare la pena de expulsión no podrá regresar al territorio nacional en un plazo de diez años, contado desde la fecha de la sustitución de la pena" (artículo 34, Ley 18.216).

Los actores clave entrevistados llamaron la atención sobre la semejanza de este plazo con el fijado por el Plan de retorno, estipulado en 9 años. Es decir, tanto los regímenes de expulsión como el Plan de retorno tienen efectos jurídicos semejantes, ya que suponen la prohibición de regreso por un período determinado o indefinido de tiempo, pero sin el control de la efectiva protección de los derechos humanos que ofrecen los Tribunales de Justicia cuando se trata del régimen penal. Desde este punto de vista, consigue los mismos efectos que los regímenes de expulsión, pero legitimándolos con consideraciones humanitarias, lo que evidencia el carácter retórico de estos argumentos a los que se recurre.

Los actores clave especialistas en derecho entrevistados para el estudio coinciden con los señalamientos centrales de este análisis. Un abogado miembro de una organización para migrantes lo explicaba en estos términos:

En este caso no hay una causa legal que motive ese número de años, porque el número de años se establece según el peso de la falta y/o delito, que en este caso no existe, en tanto, supuestamente, se trata de un plan de retorno y no de expulsión. Cualquier decisión del Estado debe ser motivada, pero aquí no hay causa legal sino económica y política, mandando un mensaje de que no es tan fácil estar en Chile (entrevista a abogado miembro de organización para migrantes, 21/3/19).

Estas aristas del Plan que, en un análisis cuidadoso, diluyen el argumento humanitario, sumadas al hecho que hasta el momento solo se dirigieran a la población haitiana, han contribuido a que los especialistas, las organizaciones de y para migrantes en general, y aquellas vinculadas con la comunidad haitiana en particular, que se entrevistaron para este estudio, consideraran que el Plan constituye una medida de expulsión indirecta, y además abiertamente discriminatoria:

Las organizaciones haitianas entendieron el plan de retorno como una expulsión velada, e incluso mal hecha, porque acá se informó mal (entrevista a miembro de organización de migrantes, 17/1/2019).

Es un plan que discrimina, sobre todo a los haitianos, porque ese plan es por este momento, según lo que entendí, solamente para los haitianos. Es una discriminación hacia nosotros, y creo que también nos hace más mal que bien [...]

protección en favor de 160 ciudadanos haitianos que se acogieron al Plan que se está analizando, que fue rechazado. Allí se discute la razonabilidad de la prohibición de regreso que contempla el plan, y en el considerando octavo se señala que "la recurrida ha explicitado todas y cada una de las razones que motivaron la dictación de la Resolución Exenta $\mathrm{N}^{\circ}$ 5.744, de 2018”, entre las que se encuentran que obedece a hechos de notoriedad y escrutinio público, a la legislación nacional, al contexto internacional y "la coherencia que la misma tendría con Convenios Internacionales que se encuentran vigentes", por lo que a juicio de la Corte "no se visualiza ningún atisbo de reproche en la prohibición incorporada a la misma". 
Analizamos que es como una deportación... cómo puedo decir... Es como una deportación porque la persona no puede volver al país hasta por 9 años, es como una deportación forzada, o deportación voluntaria (entrevista a miembro de organización haitiana, 18/1/2019).

Se puede concluir fundadamente, entonces, que la medida revela un propósito expulsor, de carácter selectivo. ¿Cómo es entonces que el discurso humanitario y de derechos humanos resulta funcional a esta operación? El próximo apartado se dedica a reflexionar en torno a esta pregunta.

\section{El discurso humanitario como fundamento de expulsabilidad selectiva}

La lectura que queremos proponer en este artículo en relación con el programa analizado, y que constituye una respuesta a la pregunta que sintetiza el problema de investigación de este estudio, es que esta articulación entre discurso humanitario y políticas con efectos restrictivos y expulsores puede explicarse a la luz del enfoque de la gobernabilidad migratoria (Domenech, 2011, 2018), que las medidas analizadas señalan explícitamente como fundamento, y que ha ido definiendo la política migratoria chilena al menos desde mediados de la década de 2000. El Plan de retorno, entonces, constituiría un ejemplo puntual del modo en que se recurre al discurso humanitario y de los derechos humanos como fundamento de la expulsabilidad selectiva desde este enfoque o paradigma, que como señalamos, está en la base del régimen global de gestión/control de las migraciones contemporáneo. Este régimen toma formas específicas a escala regional, y nacional, que a su vez se van transformando en el tiempo, respondiendo a la dinámica de los flujos migratorios, como vimos que ha estado ocurriendo en el escenario sudamericano en reacción al incremento de la migración haitiana hacia el subcontinente. Ahora bien, aunque esta articulación contextual del régimen global le imprime particularidades -que sería importante sistematizar y analizar para el caso chileno-, hay elementos generales que caracterizan su operación.

Eduardo Domenech, quien ha analizado las políticas migratorias sudamericanas desde hace más de una década, ha documentado las principales medidas y prácticas de control de las migraciones y las fronteras que se han estado desarrollando en la región: restricciones de los visados; expulsión o deportación; creación de centros de detención de extranjeros; programas de regularización migratoria; militarización de las fronteras para el "combate" al narcotráfico, el tráfico y la trata de personas, además de programas específicos dirigidos a estos dos últimos "fenómenos"; uso de tecnologías de control biométrico; programas de "retorno voluntario asistido" y "reasentamiento" son algunos de los ejemplos (Domenech, 2017), varios de los cuales se han implementado en Chile. 
El análisis de estas políticas y prácticas más allá de las fronteras nacionales ha permitido observar las líneas de continuidad que las conectan -las que por supuesto no están exentas de tensiones y contradicciones-, los argumentos coincidentes que les sirven de sustento, los actores que están detrás de la elaboración y difusión de estos argumentos, entre otros aspectos (por ejemplo, Santi, 2011; Magliano y Clavijo, 2011; Domenech, 2015). La repetición de estas políticas y programas en diferentes países, y respecto de determinados tipos de migrantes -muchas veces los mismos grupos nacionales-, representan una materialización de este régimen global de gestión/control de las migraciones.

Como señalamos ya, la gobernabilidad migratoria -en la versión sudamericana en este caso- es el enfoque que opera como base argumental de este régimen. Este enfoque ha ido institucionalizándose en el Estado chileno desde hace al menos una década, en un proceso complejo en el que se van vinculando, de maneras no necesariamente articuladas, actores globales, regionales, nacionales y locales. Un breve repaso de sus primeras materializaciones normativas es importante porque permite apreciar, por una parte, la condensación de los puntos nodales que entraman el discurso de la gobernabilidad migratoria, y por la otra, la simplificación que supone la separación maniquea de las medidas migratorias en términos de pensamiento político de derecha o izquierda, puesto que este discurso ha atravesado el pensamiento del Estado chileno sobre migraciones en los últimos 15 años, en los que se han alternado gobiernos de izquierda y derecha.

En efecto, la presencia de este paradigma en el abordaje de la migración internacional desde el Estado chileno puede rastrearse, preliminarmente, hasta mediados de la década de 2000 (Stang, 2016). Su introducción está muy ligada a la labor de incidencia política de agencias internacionales como la OIM en algunos espacios de integración regional y foros especializados en los que Chile ha tenido presencia, además de seminarios, asesorías y proyectos conjuntos (Stang, 2020).

Uno de los primeros textos normativos que se puede considerar emblemático de la cristalización de esta perspectiva en el pensamiento de Estado chileno sobre la migración internacional es un instructivo presidencial que se aprobó en 2008, durante el primer gobierno de Michelle Bachelet (2006-2010), y que fijaba pautas y acciones futuras para una política migratoria. De hecho, la referencia a este enfoque es explícita: definiendo a Chile como "un país adecuadamente abierto a las migraciones" (apertura regulada), el instructivo sostiene que "se impulsarán medidas tendientes a fortalecer la gobernabilidad migratoria" (Instructivo Gabinete Presidencial Nº 009, 2008, p. 2), para lo que el Estado asumirá un rol activo frente al fenómeno migratorio.

En la argumentación a la que se recurre en este instructivo presidencial, la noción de seguridad, que hasta ese momento se relacionaba centralmente con el migrante como una amenaza para la seguridad nacional, se introyecta al propio proceso migratorio, y en 
consecuencia al migrante: se trataría de fomentar una migración segura, lo que significa básicamente dos cosas: proteger al propio migrante de acciones que puedan atentar contra su seguridad -“[1]a migración debe producirse en condiciones en que la vida del inmigrante no corra peligro. Para ello, se promoverán acciones que permitan prevenir y sancionar tanto el tráfico ilícito de migrantes, como la trata de personas" (Instructivo Gabinete Presidencial $\mathrm{N}^{\circ}$ 009, 2008, p. 5)-, como proteger a la sociedad nacional de los peligros que algunos migrantes puedan significar. Este elemento, el de la seguridad, se vincula de manera directa con la importancia que se asigna a la regularidad migratoria.

A grandes rasgos, esta estructura argumental ha persistido hasta la actualidad, y su materialización puede rastrearse en diversos documentos institucionales, aunque con variantes, pues estos puntos nodales van entramándose de diversas maneras según diferentes contextos y coyunturas. En ese sentido, el anclaje del enfoque de la gobernabilidad migratoria en la gestión actual, que ha implementado las medidas que son objeto de este artículo, ha adoptado un cariz más abiertamente instrumental y securitista.

Así, se ha prometido "poner orden en este hogar que compartimos, en esta, nuestra casa",15, anunciando mano dura "contra el ingreso irregular y clandestino", y denunciando un "abuso del sistema, ya que las personas que ingresan mienten sobre el objetivo de su visita al país"16 (en el caso de los que entran como turistas). Este cambio de gobierno ciertamente ha tenido implicaciones en las representaciones y prácticas estatales respecto de la migración internacional, pero es importante enfatizar que, en la base, persiste este paradigma de la gobernabilidad migratoria, que permite legitimar desde la retórica de los derechos humanos y humanitaria, articulada a la de la gestión y la administración eficiente, el rol funcional que desempeña el control migratorio en el capitalismo contemporáneo. Como se pudo observar en la descripción y análisis de las medidas objeto de este artículo, y en el Plan de retorno en particular, esta matriz argumental está plasmada con claridad, a partir de varias de sus principales ideas-fuerza: la de "migración ordenada", que se sustenta en el nexo (construido) entre irregularidad-ilegalidad, que genera riesgos que deben prevenirse y combatirse; la división (implícita) entre flujos deseables e indeseables; el recurso a fundamentos ligados a los derechos humanos de los migrantes, y al discurso humanitario, asociado al migrante-víctima.

15 Piñera, Sebastián, "Discurso de presentación de la Reforma Migratoria", Santiago, 9 de abril de 2018, p. 2.

16 Minuta "Reforma Migratoria y Política Nacional de Migraciones y Extranjería", Ministerio del Interior y Seguridad Pública, abril de 2018, p. 1. 


\section{Conclusiones}

El análisis de las medidas tomadas en el último año respecto de la migración haitiana en Chile permite advertir su carácter restrictivo y expulsor: mientras que las visas consulares han operado desplazando el control fronterizo hasta el país de origen, y levantando una barrera administrativa que ha implicado una disminución muy significativa de los ingresos de los migrantes de este origen al país, el Plan de retorno, a pesar de su escaso alcance numérico en relación al total de migrantes de este origen que residen en Chile ${ }^{17}$, ha operado como un mecanismo de expulsión indirecta (en tanto que "voluntaria") con un efecto comunicacional relevante en relación a la imagen del escenario migratorio nacional que se busca proyectar.

Ante esta evidencia, los argumentos utilizados para justificar la génesis de estas medidas, basados en razones humanitarias y de derechos humanos, se revelan como recursos retóricos. Tanto en sus características como en su operatoria, en sus declaraciones explícitas y en sus efectos, es claro el nexo entre estas medidas y las políticas que se adscriben al paradigma de la gobernabilidad migratoria, estrechamente ligado, a su vez, a la regionalización de las políticas migratorias sudamericanas. Estas acciones de política, contextualizadas en un escenario nacional específico, tienen que entenderse entonces, necesariamente, como parte de un marco más amplio.

Con relación a las limitaciones del análisis, nos parece relevante mencionar al menos dos aspectos que, aunque no fueron abordados por el estudio, debiesen tenerse en cuenta en la complejización de esta propuesta analítica. Uno de ellos se relaciona con el hecho de no haber contemplado con mayor detalle las razones por las que estas medidas se tomaron específicamente respecto de los migrantes haitianos. Aunque se puede hipotetizar sobre varios motivos, una lectura sistemática de esta dimensión del tema requeriría exploraciones específicas. Interesa, sin embargo, poner énfasis en el carácter dinámico y variable de la construcción de migrantes indeseables y expulsables, más allá de la persistencia de esta condición. En otro trabajo, por ejemplo, se han abordado las especificidades de la expulsabilidad del migrante colombiano en la región chilena de Antofagasta (Stang y Stefoni, 2016), lo que permite advertir las variaciones espacio-temporales de estos procesos.

17 Según el Ministerio del Interior y Seguridad Pública, hasta fines de abril de 2019 habían regresado a Haití mediante este Plan 1.262 personas de ese origen, en 8 vuelos (en línea, <https://www.interior.gob.cl/noticias/2019/04/25/gobierno-hace-positivo-balance-del-plan-de-retornohumanitario-ordenado/>). Con relación a los 179.338 migrantes haitianos que, según estimaciones del INE y el DEM, residían en Chile en diciembre de 2018 (INE \& DEM, 2019), los retornados a través del Plan representan un $0,7 \%$. 
Otra ausencia relevante es la consideración de la agencia migrante frente a estos mecanismos de control y restricción que impone el Estado. Las luchas cotidianas de los migrantes, más o menos organizadas, para sortear esos controles, resistirlos, impedirlos, y eventualmente diluirlos, son un aspecto ineludible de estas políticas de control y restricción de la movilidad, que es necesario visibilizar, aunque no fueran el objeto de exploración y análisis de este estudio.

\section{Referencias bibliográficas}

Bauman, Z. (2003). La globalización. Consecuencias humanas. México, DF: Fondo de Cultura Económica.

Castro, E. (2004). El vocabulario de Michel Foucault. Un recorrido alfabético por sus temas, conceptos y autores. Buenos Aires: Prometeo/Universidad Nacional de Quilmes.

Cejas, I. (2015). Migraciones haitianas en la región andina. AndinaMigrante, 19, 2-13.

CIDH (Comisión Interamericana de Derechos Humanos) (2010). Informe de seguimiento sobre la situación de derechos humanos en Haití. En Informe anual de la Comisión Interamericana de Derechos Humanos. Recuperado de http://www.cidh.oas.org/annualrep/2010sp/indice2010.htm

DEM (Departamento de Extranjería y Migración) (2016). Primer Boletín informativo. Migración haitiana en Chile. Recuperado de https://www.extranjeria.gob.cl/media/2016/09/boletin-1.pdf

De Genova, N. (2002). Migrant "illegality" and deportability in everyday life. Annu. Rev. Anthropol., 31, 419-447. Recuperado de https://doi.org/10.1146/annurev.anthro.31.040402.085432

Deleuze, G. (1991). Foucault. México, DF: Paidós.

"Discurso de presentación de la Reforma Migratoria", Presidencia de la República, Gobierno de Chile (2018).

Domenech, E. (2011). La gobernabilidad migratoria en la Argentina: hacia la instauración de políticas de control con "rostro humano". Presentado en IV Congreso de la Red Internacional de Migración y Desarrollo, Quito.

Domenech, E. (2013). Las migraciones son como el agua»: Hacia la instauración de políticas de «control con rostro humano. Polis, Revista Latinoamericana, 35, 1-21.

Domenech, E. (2015). O controle da imigração "indesejável": expulsão e expulsabilidade na América do Sul. Ciencia y Cultura, 67(2), 25-29. 
Domenech, E. (2017). Las políticas de migración en Sudamérica: elementos para el análisis crítico del control migratorio y fronterizo. Terceiro Milênio: Revista Crítica de Sociologia e Política, 8(1), 19-48.

Domenech, E. (2018). Gobernabilidad migratoria: producción y circulación de una categoría de intervención política. Temas de Antropología y Migración, 10, 83-128.

Foucault, M. (1983). El discurso del poder. México, DF: Folios.

Gil Araujo, S. (2010). Las argucias de la integración. Políticas migratorias, construcción nacional y cuestión social. Madrid: Iepala.

INE (Instituto Nacional de Estadística). (2018). Características de la inmigración internacional en Chile, Censo 2017. Santiago: INE Chile.

INE (Instituto Nacional de Estadística), y DEM (Departamento de Extranjería y Migración). (2019). Estimación de Personas Extranjeras Residentes en Chile. Presentado en Santiago.

IPPDH (Instituto de Políticas Públicas en Derechos Humanos del MERCOSUR), y OIM (Organización Internacional para las Migraciones). (2017). Diagnóstico regional sobre migración haitiana. Buenos Aires: IPPDH y Oficina Regional de OIM para América del Sur.

Instructivo Gabinete Presidencial N 009 "Imparte instrucciones sobre la 'Política Nacional Migratoria'”, Presidencia de la República, Gobierno de Chile (2008).

Kalm, S. (2008). Governing Global Migration. Lund: Lund University.

Laclau, E. y Mouffe, C. (1987). Hegemonía y estrategia socialista. México DF: Siglo XXI.

Magliano, M. J., \& Clavijo, J. (2011). La trata de personas en la agenda política sudamericana sobre migraciones: la securitización del debate migratorio. Análisis político, 71, 149-163.

Mallimaci, A. \& Pedone, C. (2019). Migraciones Venezolanas en Argentina. Trayectorias migratorias y arreglos familiares. Ponencia presentada en IX Congreso Iberoamericano de Estudios de Género, Mar del Plata, Argentina.

Mármora, L. (2003). Políticas migratorias consensuadas en América Latina. Estudios Migratorios Latinoamericanos, 17(50), 111-142.

Martínez, J., \& Orrego, C. (2016). Nuevas tendencias y dinámicas migratorias en América Latina y el Caribe. Santiago: CEPAL.

Mezzadra, S. (2005). Derecho de fuga. Migraciones, ciudadanía y globalización. Madrid: Traficantes de Sueños.

Mezzadra, S. (2012). Capitalismo, migraciones y lucgas sociales. La mirada de la autonomía. Nueva Sociedad, 237, 159-178.

Mezzadra, S., \& Neilson, B. (2016). La frontera como método. O la multiplicación del trabajo. Buenos Aires: Tinta Limón. 
Minuta "Reforma Migratoria y Política Nacional de Migraciones y Extranjería", Ministerio del Interior y Seguridad Pública, Gobierno de Chile (2018).

Muñoz Ruiz, J. (2014). La expulsión penal. Nuevas tendencias legislativas, Revista Electrónica de Ciencia Penal y Criminología (16-05), 05:1-05:44.

Nieto, C. (2014). Migración haitiana a Brasil. Redes migratorias y espacio social transnacional. Buenos Aires: CLACSO.

OIM (Organización Internacional para las Migraciones) (2018). A framework for assisted voluntary return and reintegration. Recuperado de https://publications.iom.int/es/system/files/pdf/a_framework_for_avrr_en.pdf

OIM (2003). World Migration Report 2003: Managing Migration: Challenges and Responses for People on the Move. Ginebra: International Organization for Migration.

Pacecca, A. I. (2018). "Trata de personas": categoría jurídica, hecho social y narrativa contemporánea. Temas de Antropología y Migración, 10, 102-109.

Resolución Núm. 5.744 exenta "Dispone Plan humanitario de regreso ordenado al país de origen de ciudadanos extranjeros", Ministerio del Interior y Seguridad Pública, Subsecretaría del Interior, Gobierno de Chile (2018).

Rojas Pedemonte, N., Amode, N., y Vázquez, J. (2017). Migración haitiana hacia Chile: origen y aterrizaje de nuevos proyectos migratorios. En N. Rojas Pedemonte y J. Koechlin (Eds.), Migración haitiana hacia el sur andino (pp. 65-172). Lima: Universidad Antonio Ruiz de Montoya, UAH, SJM y OBIMID.

Rojas Pedemonte, N.; Amode, N. y Vásquez, J. (2015). Racismo y matrices de "inclusión" de la migración haitiana en Chile: elementos conceptuales y contextuales para la discusión. Polis, Revista Latinoamericana 14 (42), 217-245. Recuperado de http://www.scielo.cl/pdf/polis/v14n42/art_11.pdf

Santi, S. (2011). El nuevo orden migratorio global: el papel de la Organización Internacional para las Migraciones (OIM) en la Conferencia Sudamericana sobre Migraciones. Ponencia presentada en V Encuentro del Centro de Reflexión en Política Internacional (CERPI), La Plata, Argentina.

Stang, F. (2020). Seguridad y derechos, el nudo gordiano de las migraciones contemporáneas. Reflexiones sobre Chile en el escenario latinoamericano. En: R. Dufraix, R. Ramos y D. Quinteros, Securitización de las fronteras y criminalización de las migraciones. Santiago: Editorial Jurídica de Santiago (en prensa).

Stang, F. (2016). De la Doctrina de la Seguridad Nacional a la gobernabilidad migratoria: la idea de seguridad en la normativa migratoria chilena, 1975-2014. Polis, 15(44), 83-107.

Stang, F., y Stefoni, C. (2016). La microfísica de las fronteras. Criminalización, racialización y expulsabilidad de los migrantes colombianos en Antofagasta, Chile. Astrolabio, 17, 42-80. 
Thayer, E., Stang, F., y Abarca, C. (2017). Estatus legal precario y condicionalidad en el acceso a derechos. Una aproximación a la regulación migratoria de Argentina y Canadá. Si Somos Americanos. Revista de Estudios Transfronterizos, 16(2), 11-43.

Tijoux, M. E. (2016). Racismo en Chile. La piel como marca de la inmigración. Santiago de Chile: Editorial Universitaria.

Trabalón, C. (2018). Política de visado y regulación de las fronteras. Un análisis desde la movilidad de haitianos en Sudamérica. Polis, Revista Latinoamericana, 51, 163 186. 